\title{
Angioid streaks
}

\section{Ophthalmoscopic variations and diagnostic problems}

\author{
JERRY A. SHIELDS, JAY L. FEDERMAN, TERRANGE L. TOMER, \\ AND WILLIAM H. ANNESLEY, JR. \\ From the Retina Service, Wills Eye Hospital, Philadelphia
}

The clinical significance and ophthalmoscopic features of angioid streaks have received considerable attention in the ophthalmic literature (Paton, 1962; Paton, 1972; Connor, Juergens, Perry, Hollenhorst, and Edwards, I961). Angioid streaks usually have a characteristic ophthalmoscopic appearance and diagnosis is easy. In some instances, however, they may be subtle or may simulate other more common fundus conditions and the diagnosis may be more difficult. The ophthalmoscopic variations are discussed in this report with some of the more common diagnostic problems which occurred in a large series of patients with angioid streaks. These problems may be overcome by recognizing the variable clinical manifestations of this condition.

\section{Methods}

All patients with angioid streaks of the ocular fundus who were evaluated and photographed on the Retina Service of Wills Eye Hospital between March 1967 and February 1974 were included in this study. Most patients had repeated evaluations by one or more of the authors during a follow-up period of 6 months to 7 years. The clinical records, fundus photographs, and fluorescein angiograms were reviewed. The ophthalmoscopic variations and diagnostic problems which occurred were evaluated in detail.

\section{Results}

From March 1967 until February 1974, 56 patients with angioid streaks were evaluated and photographed. The diagnosis in each case was established by observing the typical fundus features of this condition (Paton, 1962; Paton, 1972; Connor and others, 1961). All cases were bilateral.

The ages of the patients ranged from 16 to 76 years (mean 49). There were 50 whites and 6 blacks; 32 women and 24 men.

Address for reprints: J. A. Shields, MD, Retina Service, Wills Eye Hnspital, 1601 Spring Garden Street, Philadelphia, Penna. 19130 Presented in part at the annual Meeting of the Section on Ophthalmology of the American Medical Association, Chicago, Illinois, 24 June, 1974. Supported in part by the Retina Research and Development Foundation, Philadelphia, and the Lions Club of Pennsylvania.
Although it was not our primary purpose to determine the incidence and type of associated systemic diseases, we listed those in which the data were readily available, and in other cases we made the medical diagnosis after the angioid streaks were recognized in our clinic. A diagnosis of pseudoxanthoma elasticum (PXE) was made on the basis of clinical examination or by skin biopsy in $3^{0}$ cases (54 per cent). Two patients had sickle cell disease. None was known to have Paget's disease. A I6-year-old white male with angioid streaks and a confirmed diagnosis of pseudoxanthoma elasticum had physical features compatible with Marfan's syndrome. A few had mild cardiovascular disease. The remainder either had no evidence of medical disease, or the medical data were insufficient.

The visual acuities ranged from $6 / 6$ to hand movements. No patient was completely blind, despite extensive macular involvement in some. One had chronic open-angle glaucoma. No significant abnormalities were present in refractive errors, ocular adnexae, anterior segment, or vitreous.

The fundus findings of the angioid streaks were variable (Table I). The streaks demonstrated variations in distribution and colour. In addition, several associated fundus findings were frequently present.

In each case there was some degree of peripapillary chorio-retinal degeneration. The angioid streaks radiated from the peripapillary region as irregular lines of variable size and shape, lying deep to the retinal vessels. They were confined to within two disc diameters of the optic nerve head (peripapillary region) in 15 of the 56 cases ( 27 per cent) (Fig. 1 ). In $4 \mathrm{I}$ cases ( 73 per cent), they were more widespread, radiating in an irregular manner from the optic disc for variable distances into the fundus (Fig. 2). In all cases, they tapered to an end before reaching the equator. There was a tendency for the streaks to involve the macular area.

The colour of the angioid streaks was grey in 18 cases ( 32 per cent), and red in 13 ( 23 per cent). Usually, however, they were an in-between colour such as red-brown, or red-grey. In eight instances 


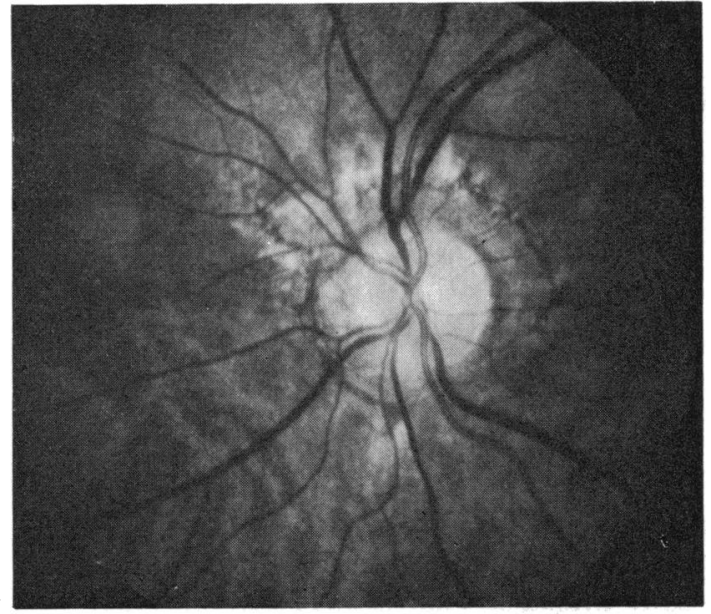

FIG. $1(a)$

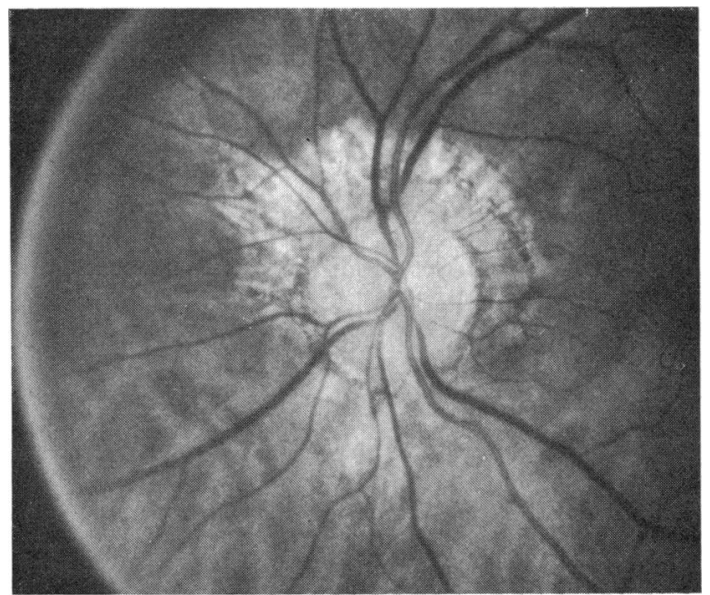

Fig. I $(b)$

FIG. I (a) Left eye of a 58-year-old white male in March 1967, showing mild peripapillary angioid streaks (b) Same eye 7 years later showing no change in appearance

(I4 per cent), there was pigment proliferation over the angioid streaks producing a black appearance (Fig. 3).

Several associated fundus changes were present (Table I). Macular degeneration, usually bilateral, was present in $4^{0}$ of the $5^{6}$ patients ( 72 per cent). Atrophic macular changes, characterized by pigmentary mottling, but no haemorrhages or exudates, were present in eight cases. Exudative maculopathy, characterized by haemorrhage, oedema, or white scar tissue, was present in 32 patients. Close scrutiny revealed an angioid streak close to the macula in each of these patients (Fig. 4). In several instances, the patient first sought ophthalmic care as a result of sudden macular haemorrhage, often after mild ocular trauma. This usually resolved in a few months,

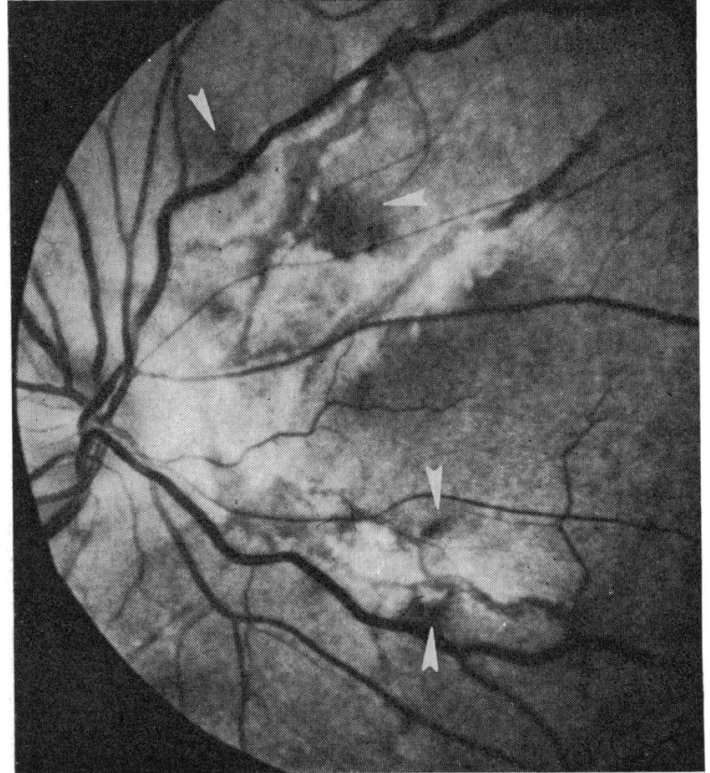

FI G. 2 More extensive angioid streaks. Note the light areas adjacent to the streaks and the paired red spots (arrows)

Table I Fundus findings in 56 patients with angioid streaks*

\begin{tabular}{|c|c|c|}
\hline Fundus findings & Number & Percentage \\
\hline \multicolumn{3}{|l|}{ Distribution of streaks } \\
\hline Peripapillary region only & 15 & 27 \\
\hline Widespread, posterior pole & $4 I$ & 73 \\
\hline \multicolumn{3}{|l|}{ Colour of streaks } \\
\hline Grey & 18 & 32 \\
\hline Red & 13 & 23 \\
\hline Combination & 25 & 45 \\
\hline Pigment proliferation into streaks & 8 & 14 \\
\hline \multicolumn{3}{|l|}{ Macular degeneration } \\
\hline Atrophic 8$\}$ & 40 & 72 \\
\hline Exudative $\left.3^{2}\right\}$ & & \\
\hline Mottled fundus (Peau d'orange) & 34 & $6 r$ \\
\hline Light margins along streaks & 32 & 57 \\
\hline Peripheral focal lesions & 24 & 44 \\
\hline Fresh haemorrhage & 19 & 35 \\
\hline Paired red spots along streaks & Io & 19 \\
\hline Drusen of optic disc & 5 & 10 \\
\hline
\end{tabular}

* Since the fundus findings were usually bilateral and fairly symmetrical, this table gives the total cases, rather than the total number of eyes.

leaving a yellow fibrous scar (Fig. 5). Some patients had a fibrous tissue scar in the macula when first seen. In some instances, it was a localized mound (Fig. 4), and in most cases it was more diffuse (Fig. 6). 


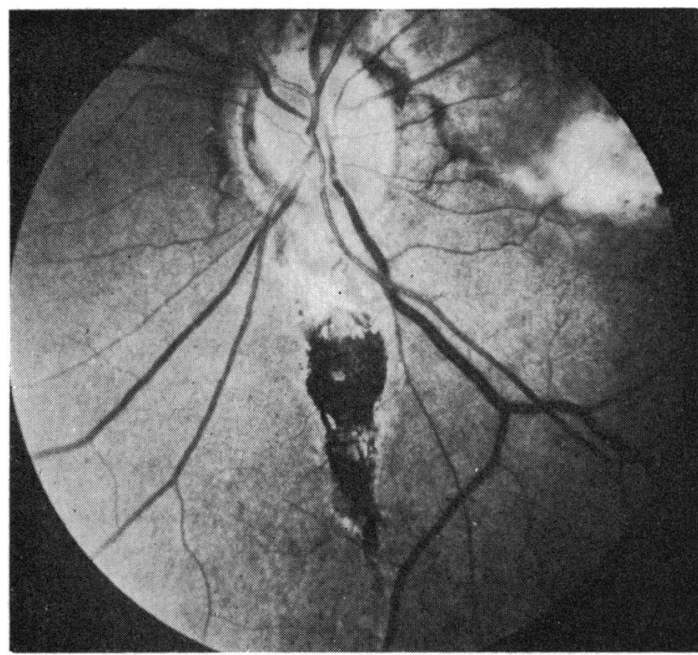

FIG. 3 Pigment proliferation into angioid streaks producing a black appearance. Note the light areas adjacent to the streaks and the disciform macular lesion to the right

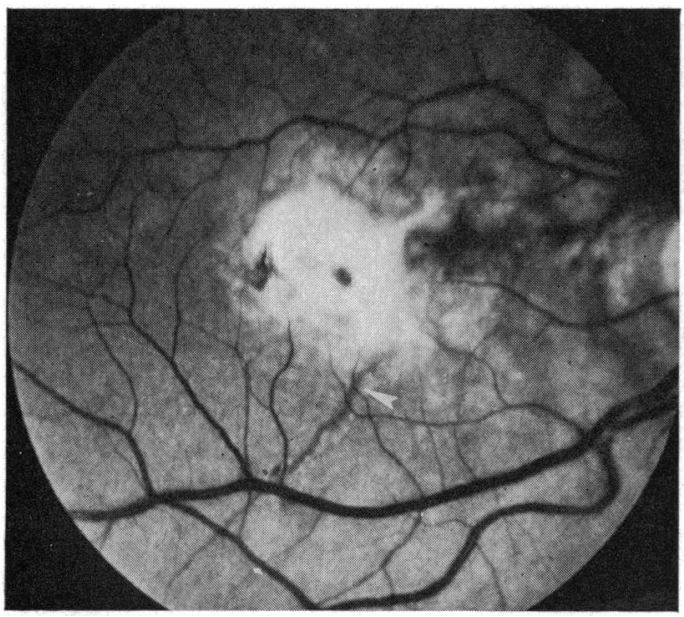

FIG. 4 Angioid streaks associated with a disciform macular scar, probably secondary to previous haemorrhage. Note the angioid streak passing through the inferior portion of the lesion (arrow)

A mottled appearance in the fundus (peau d'orange) was present in 34 patients (6I per cent). This consisted of a granular reddish-brown speckled area which usually extended from the macula towards the temporal equator (Fig. 7). In two cases it was more widespread, extending nasally to surround the optic disc. It appeared to be more common in patients with PXE.

In 32 cases ( 57 per cent) there were light areas along the margins of the streaks (Figs 2, 3, and 8). These areas extended equidistant from either edge of the streak to not more than three times the width of the streak (Fig. 8). Focal chorio-retinal lesions resembling those seen in presumed ocular histo-

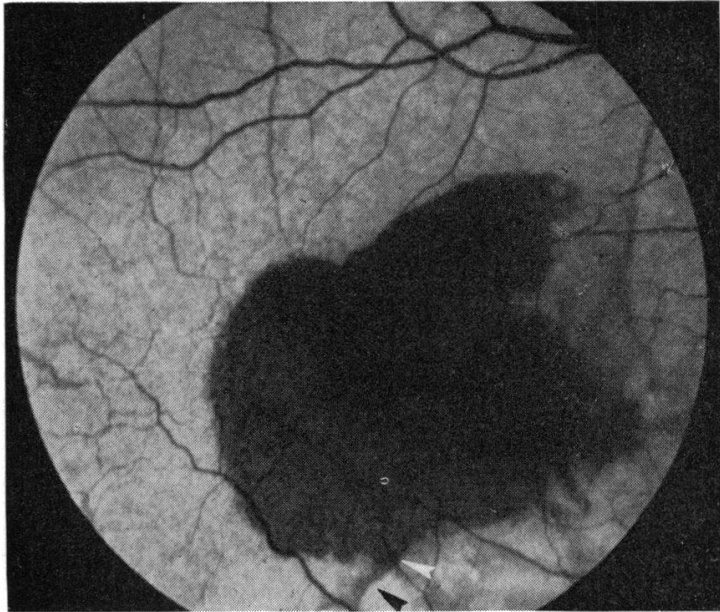

Fig. 5(a)

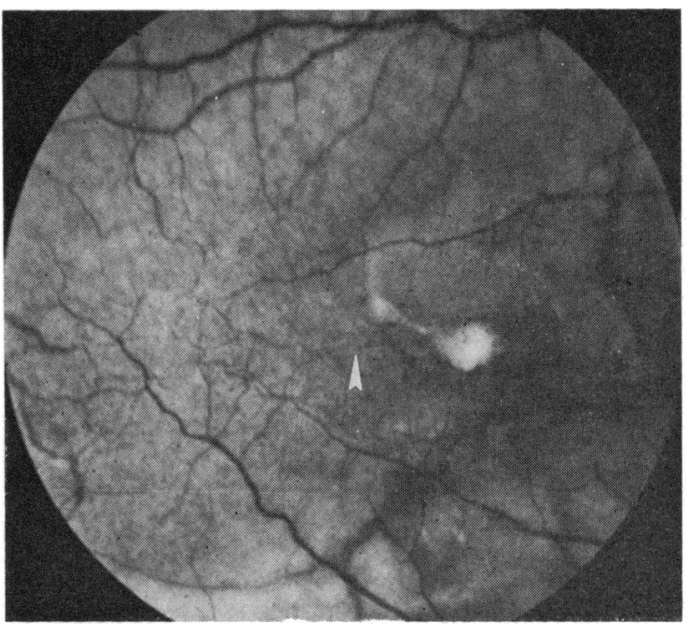

Fig. 5(b)

FIG. 5 (a) Acute macular haemorrhage in a patient with angioid streaks. Note the angioid streak inferior to the haemorrhage (b) Resolution of the haemorrhage 7 months later. Only a small mound of fibrous tissue remains and a streak is present in the area of previous haemorrhage (arrow)

plasmosis were observed in 20 cases (37 per cent). The number of such lesions in a single eye ranged from five to 30. They were often, but not always, located in close association with a streak. They varied from small, slightly elevated glistening yellow nodules without pigment to well-delineated partially pigmented spots (Fig. 9).

Fresh haemorrhages were present in 19 patients (34 per cent). They were most often located in the macular region, but could occur anywhere in the fundus along the course of the angioid streaks (Fig. 5a).

In about ten cases (19 per cent), poorly delineated, focal reddish-brown spots less than one-half disc diameter in size, were present just outside the lightcoloured area along the margins of the angioid 


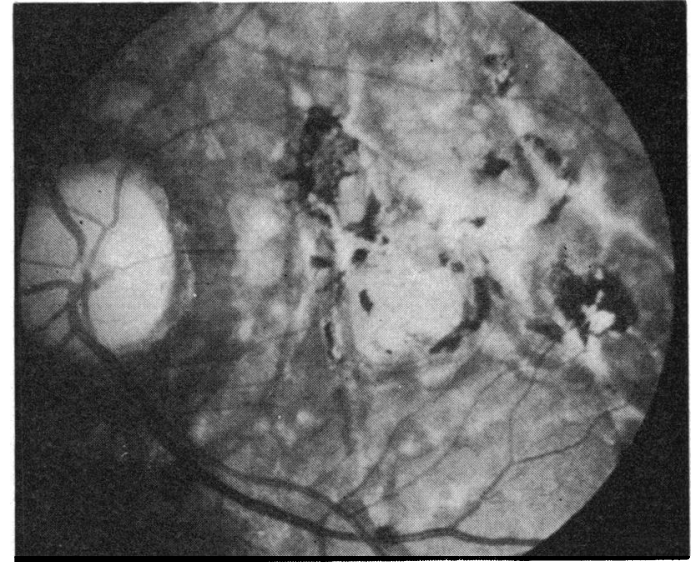

FIG. 6 Diffuse disciform macular lesion in patient with angioid streaks. Note the extensive fibrous tissue and pigment proliferation

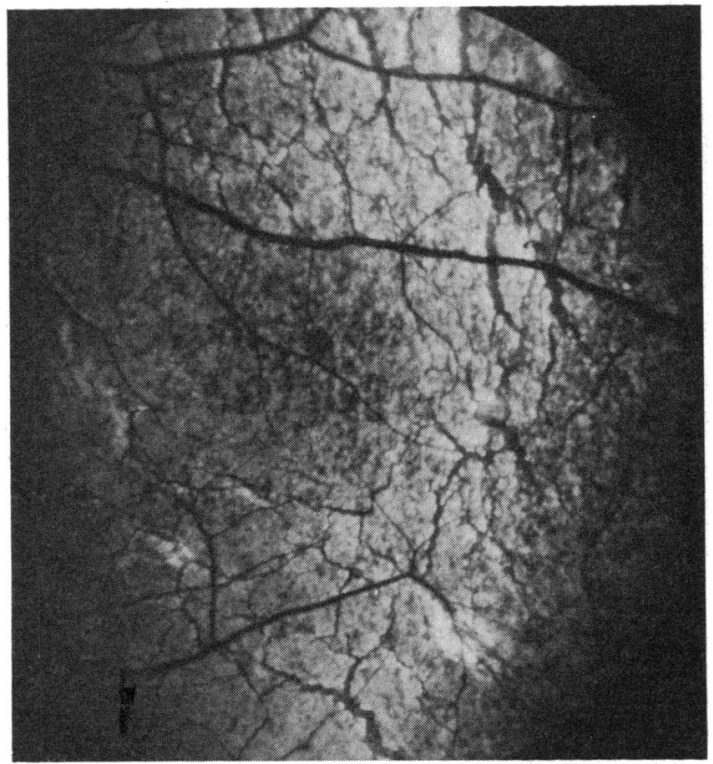

FIG. 7 Typical mottled fundus or 'peau d'orange' temporal to the macula. Note the angioid streaks within the area of involvement

streaks (Fig. 2). These always occurred in pairs, one on each side of the angioid streak. Each affected eye had from one to ten pairs of such lesions.

Another characteristic finding, usually nasal to the optic disc, consisted of numerous short vertical lines concentric to the disc margin. These resembled a cracked egg shell (Fig. 10), and appeared to be more common in blacks and young patients.

Drusen of the optic disc were present in five cases (9 per cent), and were bilateral in each instance. One patient had been evaluated neurologically because the drusen simulated papilloedema (Fig. I I).

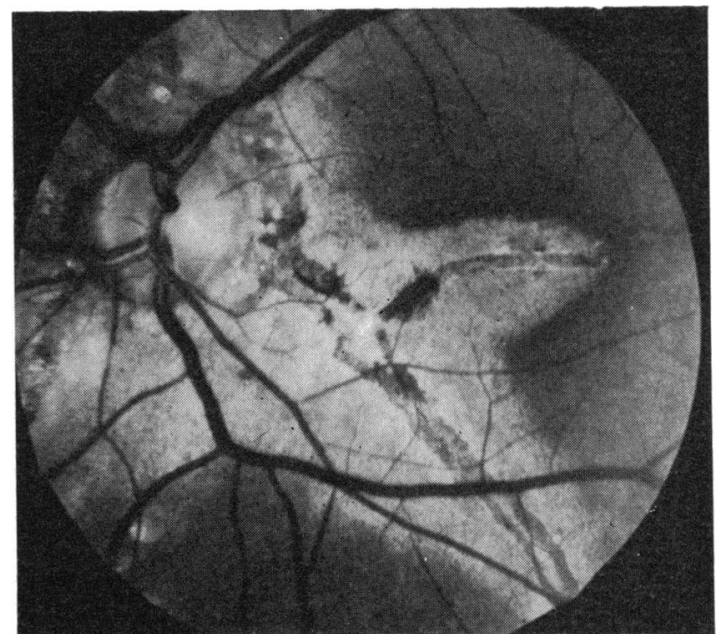

FIG. 8 Light coloured areas along the margins of angioid streaks. Note that they extend equidistant from the streak on either side

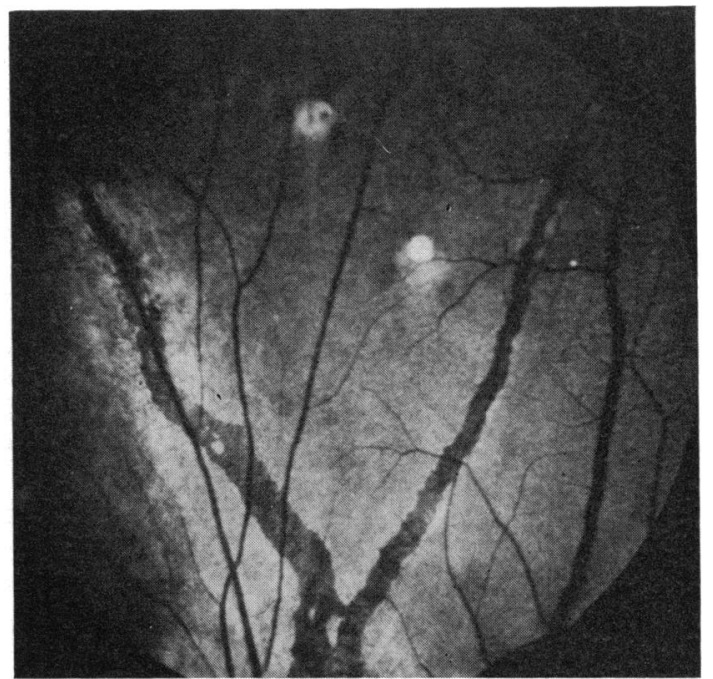

FIG. 9 Focal chorio-retinal lesions associated with angioid streaks and PXE. Note that the more inferior lesion is non pigmented, whereas the more superior one is partially pigmented

Intravenous fluorescein angiography was performed in $3^{1}$ of the $5^{6}$ patients. Contrary to most descriptions, we found that the streaks themselves were hypofluorescent during the arterio-venous phase, and most of them remained hypofluorescent throughout the angiogram, even into the late phases. There was, however, early hyperfluorescence of the yellow tissue along the margins of the angioid streaks. These areas showed progressive staining in the late angiograms which often spilled over centrally to stain the region of the streak. Close scrutiny, however, revealed that the streak remained hypofluorescent. The fluorescein 


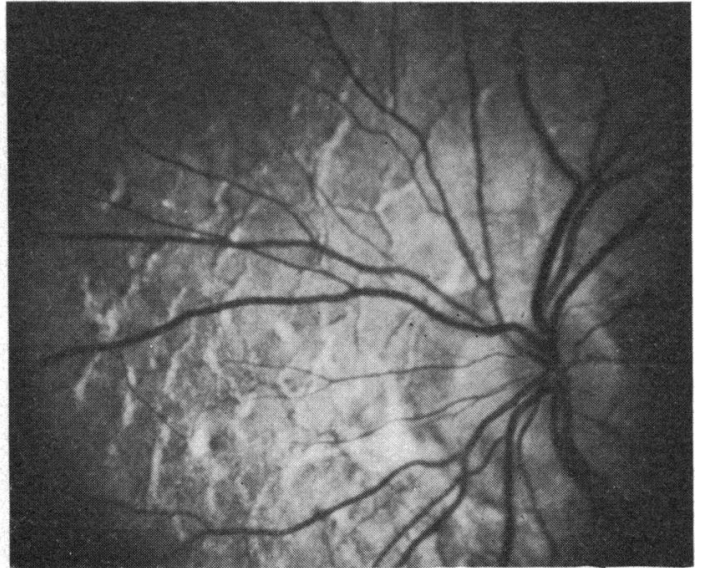

FIG. Io Cracked egg shell appearance nasal to the optic disc in a I6-year-old white male with PXE. On the nasal side, the streaks tend to develop concentric to the disc

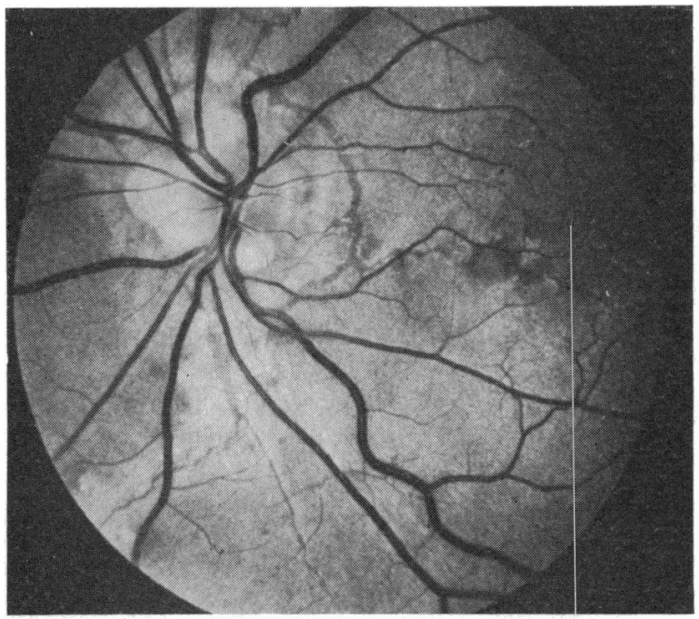

FIG. I I Drusen of the optic disc associated with angioid streaks in a 37-year-old white female with PXE. The patient was referred with the diagnosis of "papilloedema and retinal vasculitis'

angiographic features of angioid streaks in this series will be the subject of a separate report (Federman, Shields, and Tomer, 1975).

Of particular interest were some of the problems which had occurred in the ophthalmoscopic diagnosis of angioid streaks (Table II). In 16 patients (29 per cent), the diagnosis of angioid streaks had been made and the management of the case had been directed accordingly. In other cases, angioid streaks were confused with more common degenerative, inflammatory, and traumatic conditions affecting the fundus.

Degenerative conditions simulated by angioid streaks included senile macular degeneration, so-
Table II Referring diagnosis in 56 patients with angioid streaks

Diagnosis

No. of cases Percentage

Angioid streaks

Macular degeneration

I6 29

Choroidal sclerosis

13

23

Myopia

Histoplasmosis

Toxoplasmosis

Retinal vasculitis and papilloedema I

Traumatic haemorrhage

No diagnosis rendered

13
2

I

2

I

I

15

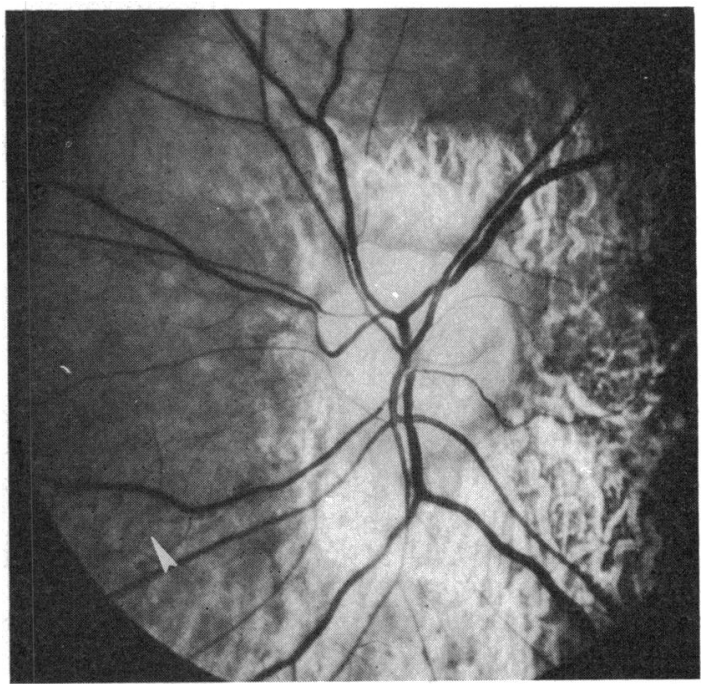

FIG. I2 Peripapillary 'choroidal sclerosis' in a patient with drusen of the optic disc. The angioid streaks are difficult to see (arrow) because of the extensive confluent peripapillary changes

called choroidal sclerosis, and myopia. In 13 cases (23 per cent), the ophthalmologist had made the diagnosis of macular degeneration but had failed to consider angioid streaks as the underlying cause (Fig. 4). In some cases, the peripapillary chorioretinal changes were so diffuse that the angioid streaks were no longer detectable. Examination of a 55-year-old white female referred because of 'choroidal sclerosis', revealed no clearly detectable angioid streaks, but prominent drusen of the optic discs (Fig. 12). Suspecting PXE, we arranged to examine other family members, and her younger brother was found to have classical angioid streaks (Fig. I3). Both siblings were subsequently proved to have PXE. One patient was referred with a diagnosis of chorioretinal degeneration probably because of myopia. Examination revealed angioid streaks but no significant myopia. 


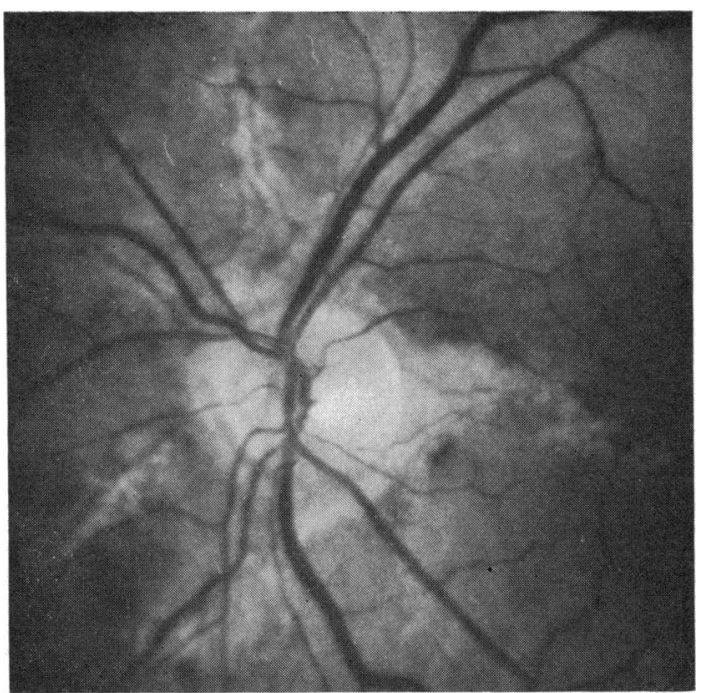

FIG. I3 Fundus of asymptomatic brother of patient shown in Fig. 12, illustrating typical angioid streaks

Inflammatory conditions simulated by angioid streaks included histoplasmosis, toxoplasmosis, and retinal vasculitis. In two patients, the peripapillary, macular, and peripheral changes had led to the erroneous diagnosis of ocular histoplasmosis. One was a 46-year-old woman who had been diagnosed at a major eye institute as having ocular histoplasmosis; she had been treated periodically for 2 years with systemic and retrobulbar steroids with no improvement. Fundus examination in our clinic revealed angioid streaks with peripapillary, macular, and peripheral lesions in both eyes (Fig. I4). The diagnosis

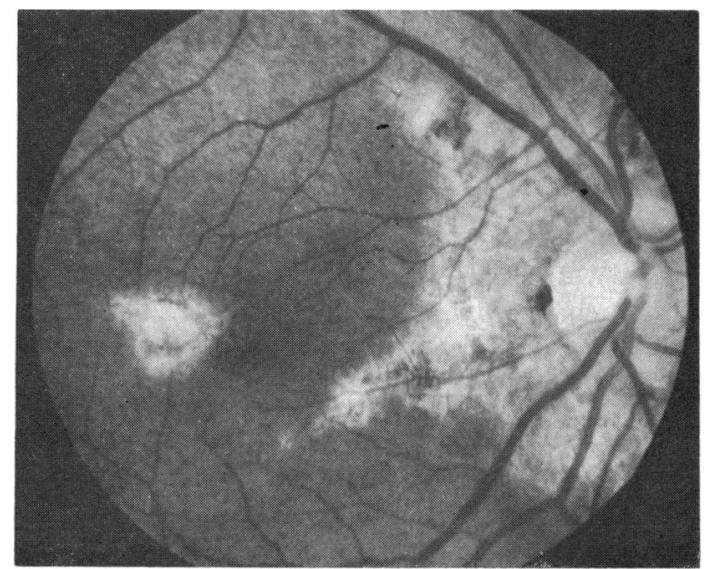

FIG. I4 Peripapillary angioid streaks and macular changes in a 46-year-old white female treated at another institution for ocular histoplasmosis. There were numerous peripheral focal lesions as well. The true diagnosis was $P X E$

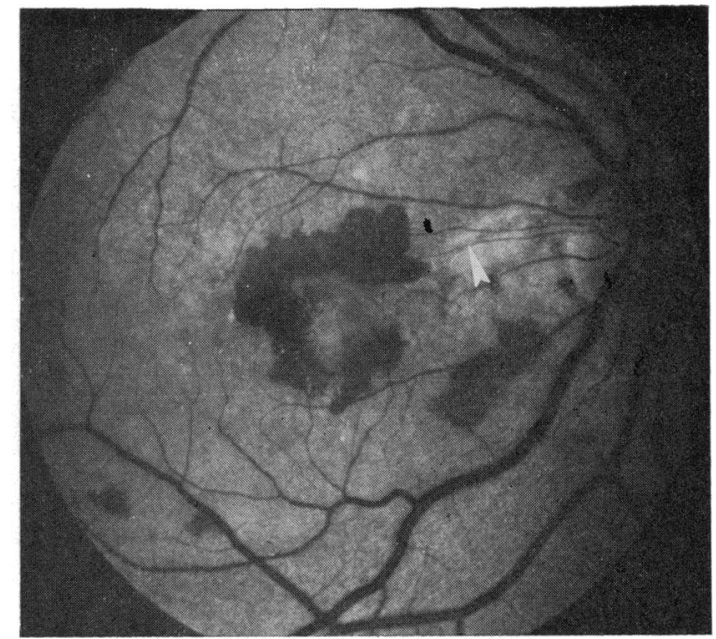

FIG. I5 Focal haemorrhagic macular nodule simulating histoplasmosis in a 57-year-old white female with angioid streaks and PXE. Note the angioid streak deep to the papillomacular bundle (arrow)

of PXE was subsequently confirmed, and the evaluation for histoplasmosis was negative. In several cases, a fresh haemorrhagic nodule in the macula was highly suggestive of histoplasmosis (Fig. I5).

In one case angioid streaks were mistaken for ocular toxoplasmosis. A 30-year-old black female had been followed-up for 6 years with a diagnosis of toxoplasmosis because of a large pigmented macular lesion and several pigmented lesions in the adjacent fundus. Examination in our clinic revealed that each

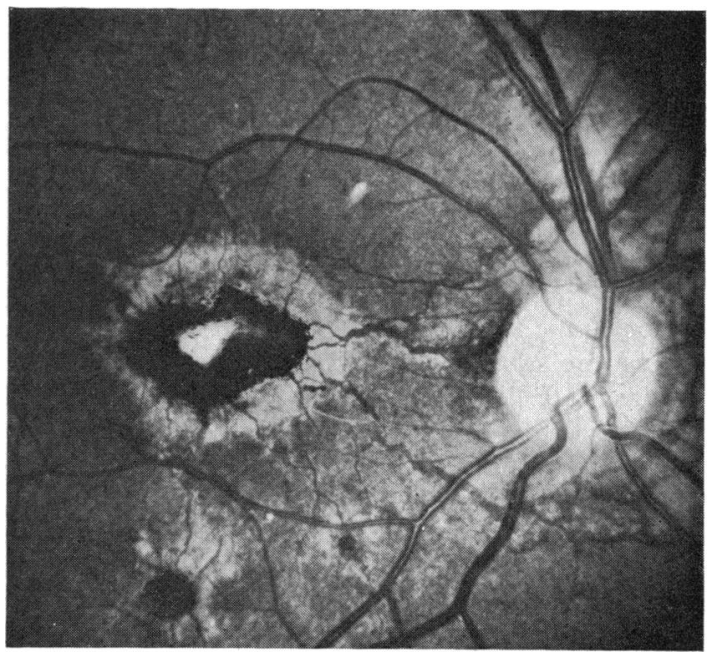

FIG. I6 Pigmented macular lesion simulating toxoplasmosis in a 30-year-old black female with PXE.

The patient had been followed-up for 6 years with a diagnosis of toxoplasmosis before the angioid streaks were detected 
pigmented lesion was closely associated with an angioid streak and the diagnosis of PXE was subsequently confirmed (Fig. I6).

As the name implies, angioid streaks may superficially resemble blood vessels. One 37-year-old white female was referred with the diagnosis of 'papilloedema and retinal vasculitis'. The true diagnosis was drusen of the optic disc and angioid streaks (Fig. I I). Skin biopsy subsequently proved that the patient had PXE. In some cases haemorrhage following mild ocular trauma was the initial clinical manifestation of angioid streaks and the diagnosis of traumatic retinal haemorrhage was made without recognizing the angioid streaks. An I8-year-old white female had blunt trauma to the right eye and was found to have numerous retinal haemorrhages. Close examination revealed that the haemorrhages had occurred along the course of angioid streaks (Fig. I 7). The patient was subsequently proved to have PXE.

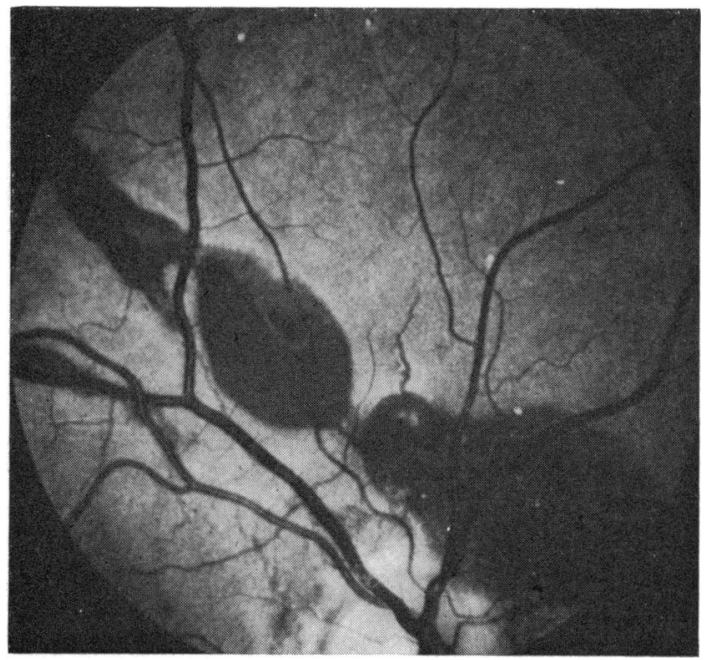

FIG. I 7 Haemorrhages along the course of angioid streaks following blunt ocular trauma in an 18-year-old white female who was previously asymptomatic. Subsequent evaluation confirmed the diagnosis of $P X E$

\section{Discussion}

The clinical significance of angioid streaks has received considerable attention (Paton, 1962; Paton, 1972; Connor and others, 1961). Its relationship to pseudoxanthoma elasticum (PXE) is well documented (Connor and others, I96r; Bischler, 1956; Cowper, 1954; Erbakan, 1961; Gills and Paton, 1965; Hagedoorn, I939; Klien, I949; Scholz, 1941; Voisin and Lombard, 1955; Clay, 1932; Rosen, 1968; Shimizu, 1961). It appears to be significantly related to Paget's disease, (Paton, 1962; Paton, 1972; Terry, 1934; Gass and Clarkson, 1973) sickle cell disease, (Paton, 1962; Paton, 1972;
Paton, 1959; Geeraets and DuPont, 1960) and possibly other conditions (Green, Friedman-Kien, and Banfield, I966; Howard, I963; Wright, I964; McPhaul and Engel, I96r; Percival, I968; Scheie and Hogan, 1957; Yatzkan, 1957; Kalina, 1970). Fluorescein angiography has been found useful in their recognition (Smith, Gass, and Justice, I964; Patnaik and Malik, I97I). Of great importance to the ophthalmologist are the ophthalmoscopic variations of angioid streaks. Previous clinical observations are confirmed in this report, relative incidence of the various fundus features are elaborated upon, and diagnostic problems which the ophthalmologist may encounter are discussed.

In those patients having widespread angioid streaks (72 per cent), recurrent haemorrhages and exudative macular changes were frequent. In those with only mild peripapillary streaks ( 28 per cent), there were usually no associated fundus abnormalities, macular lesions did not occur, and good vision was maintained. An example of this was the patient who showed no change over a 7 -year period (Fig. I). He remained asymptomatic with perfect vision. No systemic disease could be diagnosed, despite extensive evaluation and skin biopsy. It is tempting to speculate that angioid streaks with this appearance have a benign course and offer a good visual prognosis. On the other hand, patients with associated findings such as a mottled fundus or drusen, are more likely to have PXE or other systemic disease and have a tendency to develop macular changes and visual loss.

The colour of the angioid streaks appeared to be unrelated to systemic disease, associated fundus changes, or prognosis. Paton (1972) relates the colour of the angioid streaks to the pigmentation of the individual eye.

It is not uncommon for angioid streaks to be associated with extensive proliferation and migration of the retinal pigment epithelium (Figs 3 and 16). This is particularly true in black patients and may lead to diagnostic confusion (Fig. I6).

In this series, 72 per cent of the patients had some degree of macular degeneration, which was usually bilateral (Figs 4-6). This agrees with the series of Connor and others ( $196 \mathrm{I}$ ) in which the incidence was 73 per cent. The macular lesion usually consisted of haemorrhage and scar tissue probably secondary to fibrovascular tissue growing into the streak from the choroid. With recurrent haemorrhages, the macular involvement becomes more extensive. Since patients with macular involvement are normally apprehensive, it is important to inform them that this condition does not usually cause complete blindness, but that their central vision may be permanently impaired.

The so-called mottled fundus (peau d'orange) seen in 6 I per cent of our cases, is a highly characteristic finding in patients with PXE (Bischler, 1956; Gills 
and Paton, 1965; Gass, 1970). This gives a speckled appearance to the fundus, usually most pronounced temporal to the macula (Fig. 7). This finding may precede the development of angioid streaks (Bischler, 1956; Gass, 1970). We have observed angioid streaks develop in areas with such involvement (Fig. 7).

About 57 per cent of the patients in this series demonstrated light areas coursing along the margins of the angioid streaks (Figs 2, 3, 8, and 9). There is little discussion in the literature as to their histological counterpart. Gass and Clarkson (1973); Gass (1970) feel that they may represent both thinning of the retinal pigment epithelium and a fibrovascular membrane growing through the angioid streak into the space beneath the retinal pigment epithelium.

Focal chorio-retinal lesions were present in 44 per cent of our cases. These have been called 'salmon spots' (Smith and others, I964; Krill, Klien, and Archer, 1973) and are similar to the 'punched-out' lesions seen with ocular histoplasmosis (Paton, I972). Their relationship to angioid streaks and PXE is obscure.

Fresh haemorrhages were noted in the fundus of 35 per cent of the patients (Figs $5 a, 15$, and 17 ). These occurred along the course of the angioid streaks, most commonly in the macular area. Recurrent haemorrhages in this region are the principal cause of visual loss in patients with angioid streaks. There appears to be a relationship between ocular trauma and retinal haemorrhage in patients with angioid streaks (Britten, I966), although a history of trauma may be difficult to elicit (Paton, 1972).

Paired reddish-brown spots occurred along the margins of the angioid streaks in 19 per cent of our cases (Fig. 2). To our knowledge, these have not been thoroughly discussed in previous articles, perhaps because they are subtle and may be easily overlooked unless the fundus photographs are carefully examined. We do not know the significance of this finding. They appear to be different from the dark spots within the areas of peau d'orange, mentioned by Krill and others (1973).

It is known that drusen of the optic disc are occasionally found in eyes with angioid streaks (Paton, 1972; Krill and others, 1973). This association occurred in five of our cases (Io per cent), and was found in patients with PXE in every instance. The significance of this association is uncertain.

The associated fundus findings in this series of patients were responsible for some of the problems in diagnosis. The most common problem was in making the diagnosis of senile macular degeneration and failing to recognize that angioid streaks were the underlying cause. The differentiation should not be difficult because the macular changes usually occur at a younger age in patients with angioid streaks. In addition, the degenerative process is usually more diffuse, often involving the papillomacular bundle (Fig. 6). Finally, careful fundus examination and fluorescein angiography will often reveal angioid streaks in the vicinity of the macular lesion (Figs 4 and 5).

There have been some reports of an association between so-called choroidal sclerosis and angioid streaks with PXE (Britten, 1966). One of our patients was initially thought to have this entity, but examination of the family revealed a sibling with typical angioid streaks (Figs 12 and I3). It is possible that the degeneration of the retinal pigment epithelium and the choriocapillaris may become wider and finally coalesce (Paton, 1972), so that the streaks become difficult or impossible to recognize, even with the aid of fluorescein angiography. In such instances, the fundus picture may be identical to so-called choroidal sclerosis.

The peripapillary and macular changes seen with angioid streaks may also simulate myopic chorioretinal degeneration. One of the patients in this series was referred for a retinal detachment originally thought to be related to myopia. Examination, however, revealed no significant myopia, but angioid streaks were present. Further examination revealed that the patient had signs of PXE. We have also had occasion to examine a patient with myopia who was referred with the erroneous diagnosis of angioid streaks. In most instances, however, the differentiation between angioid streaks and myopia should not be difficult, because the large disc and temporal crescent of myopia is characteristic. In addition, the macular lesion (Fuchs's spot) in myopia is usually small and discrete as opposed to the larger diffuse macular degeneration seen in angioid streaks. In high myopia, linear 'lacquer cracks' have been observed in the posterior pole. Although they may represent a similar process, they are usually isolated to the macular region and do not radiate from a peripapillary location. Of course, the refractive error of myopia would also be helpful in making the differentiation.

Angioid streaks may occasionally simulate certain inflammatory conditions of the fundus. The peripapillary, macular, and peripheral changes may resemble those of ocular histoplasmosis; this occurred in two of our cases (Figs I4 and I5). In our series, some degree of peripapillary change was present in roo per cent, macular degeneration in 72 per cent, and focal chorio-retinal lesions in 37 per cent. Most reports in the literature fail to note the close similarity between these two conditions, although Paton (1972) has mentioned that the peripheral 'punched-out' lesions seen associated with angioid streaks are similar to those seen in histoplasmosis. In 22 of our patients (40 per cent), peripapillary, macular, and peripheral focal lesions were present in the same eye simulating the histoplasmosis triad. It is important to make the proper differentiation in these cases because ocular 
histoplasmosis, an inflammatory process, is often treated with corticosteroids, whereas angioid streaks are usually associated with PXE, a heredodegenerative process, in which corticosteroids are apparently not helpful.

There are certain clinical features which should differentiate angioid streaks from ocular histoplasmosis. The macular lesion of histoplasmosis is often unilateral, whereas the macular involvement in angioid streaks is almost always bilateral. In histoplasmosis, the peripapillary chorio-retinal atrophy often follows the contour of the optic disc, whereas in angioid streaks it is more irregular. The macular lesion is usually a focal nodule in histoplasmosis, whereas in angioid streaks the macular lesion is usually more diffuse. Careful examination will often reveal the angioid streak adjacent to the macular lesion. We also feel that the peripheral focal lesions are different in the two conditions. In histoplasmosis, they appear 'punched-out' and a dull yellow-grey in colour, while in angioid streaks they are often slightly elevated and have a glistening appearance. In both instances, they may show variable pigmentation. In angioid streaks, they may represent fibrous tissue mounds at the sites of previous focal deep retinal haemorrhages, rather than inflammatory foci as seen in histoplasmosis. A detailed systemic investigation would be helpful in differentiating between histoplasmosis and PXE or other diseases associated with angioid streaks.

In rare instances, angioid streaks may be confused with ocular toxoplasmosis. This is especially true in black patients where considerable pigment proliferation may occur along the margins of the streaks. One of our patients was followed-up for 6 years with a diagnosis of toxoplasmosis because of a large partially pigmented macular lesion and several pigmented peripheral lesions. Careful examination revealed that each lesion was closely associated with angioid streaks (Fig. 16) and the diagnosis of PXE was subsequently confirmed.

As their name implies, angioid streaks may resemble blood vessels. The light areas along the margins of the streaks may give the appearance of perivascular infiltrates or sheathing and the associated haemorrhages may lead to further confusion. One of our patients who had drusen of the optic disc was thought to have papilloedema and retinal vasculitis (Fig. II). Familiarity with the clinical appearance of angioid streaks should prevent such diagnostic difficulties.

This study has shown that the clinical characteristics of angioid streaks may vary considerably. In some cases they may be so subtle that they are not recognized, and in other instances they may be seen but interpreted as something else. An ophthalmoscopic differential diagnosis of angioid streaks is presented in Table II. The macular changes which occur in over 70 per cent of the cases may be misinterpreted as 'senile macular degeneration'. Because eyes with angioid streaks may have peripapillary, macular, and peripheral lesions, they may occasionally simulate other conditions producing a similar triad, such as histoplasmosis and myopia. Since most patients with angioid streaks have pseudoxanthoma elasticum or other significant systemic diseases, the ophthalmologist should be familiar with their clinical variations and differential diagnoses.

\section{Synopsis}

Fifty-six patients with angioid streaks were evaluated ophthalmologically. Most had repeated fundus photography and fluorescein angiography during a follow-up period of 6 months to 7 years. The ophthalmoscopic variations and diagnostic difficulties which occurred were noted.

In most instances, the angioid streaks were not initially recognized and the patient was referred with another diagnosis. In several cases, the peripapillary, macular, and peripheral changes seen with angioid streaks were found to simulate other better known fundus conditions, resulting in erroneous diagnosis and improper treatment. In some cases, the angioid streaks were so subtle that they were overlooked and in others they were observed, but initially interpreted as something else. Because of the medical significance of angioid streaks, ophthalmologists should be aware of their variable features. These are discussed, with emphasis upon those subtleties which differentiate angioid streaks from other conditions which they may simulate. On the basis of these observations, an ophthalmoscopic differential diagnosis of angioid streaks is proposed.

We thank the members of the Retina Service and the Staff of Wills Eye Hospital for allowing us to evaluate their patients, and Mr Peter Breit, Ms Thea Fischer, and Ms Jean Douglas for their assistance.

\section{References}

Anderson, B. (1948) Trans. Amer. Ophthal. Soc., 46, 326

BISCHLER, v. (1956) Amer. F. Ophthal., 42, 666

BRITTEN, M. J. A. (I966) Brit. F. Ophthal., 50, 540

CLAY, G. (I932) Arch. Ophthal., 8, 334

CONNOR, P. J., JUERGeNs, J. L., PERry, H. o., hOllenhorst, R. W., and eDWARds, J. e. (1961) Amer. J. Med.,

30, 537 
COWPER, A. R. (1954) Arch. Ophthal., 51, 762 erbakan, s. (1961) Amer. F. Ophthal., 51, 704 FEDERMAN, J. L., SHIELDS, J. A., and TOMER, T. L. (1975) Angioid streaks. II, Fluorescein angiographic features. Arch. Ophthal. (in press)

GASS, J. D. M. (1970) 'Stereoscopic Atlas of Macular Diseases', Mosby, St Louis and Clarkson, J. G. (1973) Amer. 7. Ophthal., 75, 576

GEERAETS, W. J. and DUPONT, G. (I960) Ibid., 49, 450

GILls, J. P., and PATON, D. (1965) Arch. Ophthal., 73, 792

GREEN, W. R., FRIEDMAN-KIEN, A., and BANFIELD, W. G. (I966) Ibid., 76, I97

HAGEDOORN, A. (1939) Ibid., 21, 746

HOWARD, G. м. (1963) Amer. F. Ophthal., 56, 137

KALINA, R. E. (1970) Arch. Ophthal., 84, 528

KLIEN, B.A. (I949) Amer. F. Ophthal., 32, I 134

KRILL, A. E., KLIEN, B. A., and ARCHER, D. B. (I973) Ibid., 76, 875

MGPHAUL, J. J., and ENGEL, F. L. (I96I) Amer. F. Med., 31, 488

PATNAIK, B., and MALIK, s. R. K. (1971) Brit. $\mathcal{F}$. Ophthal., 55, 833

PATON, D. (1959) Arch. Ophthal., 62, 852 (1962) Mid. East med. F., r, 30 r

(1972) 'The Relation of Angioid Streaks to Systemic Disease'. Thomas, Springfield, Ill.

PERGIVAL, S. P. B. (ig68) Brit. 7. Ophthal., 52, 297

ROSEN, E. (1968) Amer. F. Ophthal., 66, 236

SCHEIE, H. G., and HOGAN, R. F. (1957) Arch. Ophthal., 57, 855

SCHOLZ, R. O. (1941) Ibid., 26, 677

SHimizu, к. (I96I) Fap. F. Ophthal., 5, I

SMITH, J. L., GASs, J. D. M., and JUSTICE, J. (I964) Brit. F. Ophthal., 48, 5 I 7

TERRY, T. L. (1934) Trans. Amer. ophthal. Soc., 32, 555

voisin, J., and lombard, J. (1955) Amer. F. Ophthal., 40, 304

WRIGHT, J. c. (1964) Brit. F. Ophthal., 48, 402

yatzkan, D. N., (1957) Amer. F. Ophthal., 43, 2 19 